\title{
Espacios funerarios y migración: contornos difusos y territorialidad en las principales provincias de acogida en los siglos XIX y XX
}

(1) Celeste Castiglione

Consejo Nacional de Investigaciones Científicas y Técnicas / Instituto de Estudios Sociales en Contextos de Desigualdades, Universidad Nacional de José C. Paz, Argentina. https://uba.academia.edu/CelesteCastiglione

Recibido: 27 de marzo de 2019. Aceptado: 2 de septiembre de 2019.

\begin{abstract}
Resumen
En las entrevistas realizadas a lo largo de los años hay un tema que se desprende como uno de los elementos que componen la historia y la trayectoria migratoria de manera privilegiada en las representaciones individuales y colectivas: la muerte. Ésta se configura como un marco referencial que responde a persistencias y transformaciones conceptuales que la sociedad y cada grupo en ella consideran como propio o representativo de su identidad. De forma tal que los rituales y los modos de evocar la muerte manifiestan parte del capital económico, social, cultural y simbólico que los migrantes poseen de acuerdo a su lugar de origen. Asimismo, el morir fuera del marco de referencia los obliga a articular formas de complementación y cooperación, así como sortear conflictos para conseguir espacios en donde enterrar a sus muertos de acuerdo a su ritualidad y performatividad identitaria. El presente trabajo es el resultado de un recorrido por 165 cementerios de las principales provincias de acogida de la migración en Argentina que arribó desde mediados del siglo XIX y principios del XX y las formas que han elegido para conmemorar a sus difuntos.
\end{abstract}

Palabras clave: Cementerios étnicos. Espacios funerarios. Migración histórica. Argentina.

Funerary spaces and migration: diffused contours and territoriality in the main host provinces in the 19th and 2oth centuries

\begin{abstract}
In the interviews made through this past few years there is a subject that stands out as one of the elements that compose the history and migratory path on a privileged way in the individual and collective representations: death. This is configurated as a referencial frame that answers to persistances and conceptual transformations that the society and every group inside of it considers as own or representative of their identity in a way that the rituals and the ways to evocate death manifest part of the economic,
\end{abstract}


social, cultural and symbolic capital that the migrants own according to their home place. Likewise, dying outside of the reference frame forces them to make ways to compliment and cooperate, as well as resolving conflicts to get spaces to bury their deads according to their rituals and identitary performance. The present essay is the result of the investigation through 165 cemeteries in the main migratory reception in Argentina that arrived from mid XIX century and begginings of the XX and the ways they have chosen to commemorate their deceased.

Key words: Ethnical cemeteries. Funerary spaces. Historical migration. Argentina.

Palavras-chave: Cemitérios étnicos. Espaços funerários. Migração histórica Argentina.

\section{Introducción}

Los cementerios poseen una función específica en la organización social desde tiempos inmemoriales. El sitio elegido para desechar el cadáver y cumplimentar con los rituales que esa sociedad tuviera para despedirlo y conmemorarlo ha sido ampliamente trabajado desde la antropología (Thomas, 1983) y la arqueología (Lull y Picazo, 1989). Dentro de los estudios liminares del campo socio histórico que es desde donde escribimos, se encuentran los trabajos de Durkheim (1897), Elías (1987), Ariés (2000).

En la Argentina la pionera de los estudios de los cementerios como fuente histórica y base de múltiples análisis es Carlota Sempé y su equipo, del cual formamos parte, así como también producciones actuales (Barile y Castiglione, 2018) nutrieron en campo.

El enfoque del presente artículo busca profundizar en los estudios que posean una mirada socio histórica que conciba al espacio como producto de la interacción social y una manifestación concreta y evidente del poder (Lefevre citado por Cravino, 2014:36). En esa línea el emplazamiento de un artefacto arquitectónico y la disposición en el terreno, se encuentran determinadas en la medida que incorporen las reglas y normativas de esa sociedad, negociando alteridades dado que "no hay identidad fuera de las relaciones de poder" (Grimson, 2000). La adquisición de cualquier espacio se encuentra cargada de luchas, complementación, cooperación y conflicto y los cementerios tampoco escapan a este dispositivo. Estas disputas se ponen aún más de manifiesto cuando tienen como una de sus principales funciones crear, sostener y reproducir identidad (Reimers, 1999), especialmente de las religiones o nacionalidades desconocidas o consideradas "exóticas" por parte de la élite dirigente del momento (Devoto, 2003:273). Por esa razón, nos interesa rastrear en los cementerios la existencia de una identificación o marca étnica que dé cuenta de que ese espacio posee un valor significativo para una minoría extranjera, permitiendo que sus miembros reproduzcan sentido, aún después de muertos.

Los cementerios son lugares polisémicos en donde la sociedad moderna permite prácticas emocionales y que al mismo tiempo generan representaciones de fascinación y rechazo, constituyéndose como "contra -espacios heterotópicos" por excelencia: lugares que inquietan, desafían, alterados por la imaginación, en donde se yuxtaponen capas, acumulando tiempo, constante y distinto, todo a la vez (Foucault, 1966). Allí, el lugar se transforma en una relación significante en donde confluyen identidad y territorio-territorialidad, adquiriendo otro sentido para los actores involucrados, transformando sus motivaciones y expectativas, evidenciando así su capacidad de acción y gestión (Mera, 2016).

El presente trabajo se organiza dando cuenta del contexto en el cual se conforma esta territorialidad, "móvil, mutable y desequilibrada" (Montañez, 1997:198). La gran mayoría de estos espacios de enterramiento adquieren características específicas, 
aunque factibles de ser agrupadas al tener elementos en común, que se han catalogado en tres grandes grupos:

»Cementerios de Disidentes: terrenos comprados para el enterramiento de miembros de la corriente protestante, especialmente ingleses, escoceses, alemanes, norteamericanos, etc.

" Cementerios judíos, musulmanes y armenios ${ }^{1}$ : terrenos adquiridos por asociaciones de estas religiones con un uso privado de días y horarios.

" Edificios funerarios que se encuentran dentro de los cementerios municipales: de religión católica, adquiridos por Asociaciones de Socorros Mutuos que ofrecían como parte de los servicios el entierro junto a sus connacionales.

En una primera parte, presentaremos el contexto histórico en el que estas necrópolis fueron pensadas y ejecutadas, en su gran mayoría; en una segunda detallaremos las características específicas del relevamiento y la confección de la selección del territorio, en donde describiremos los elementos en común de cada uno de los cementerios, su ubicación y cantidad que no puede desprenderse del contexto de ese grupo migratorio y por último, en virtud del recorrido, reflexionaremos acerca de los cementerios como espacios complejos y heterotópicos, en donde la identidad -su creación, reproducción y conservación--, y el capital comunitario, conforman espacios de rituales funerarios que permanecen hasta el presente.

\section{Presentación del escenario}

El objetivo de este trabajo es relevar los espacios de enterramiento y ritualidad de los distintos grupos étnicos que arribaron a la Argentina durante el siglo XIX y principios del XX, en el marco de la consolidación del sistema económico capitalista y las dificultades que poseía la migración masiva con un Estado en formación. Para ello es necesario presentar, aunque sea brevemente, los alcances de este contexto.

Coincidimos con que "el espacio ritual es el lugar donde se lleva a cabo una serie de prácticas religiosas de tipo ceremonial que refieren a la relación del hombre con su entorno y se realizan conforme a una liturgia particular" (Iwaniszewski y Vigliani, 2011:3)

En el Río de la Plata durante la época colonial se establecieron lugares de enterramiento en los límites de los pueblos y alrededor de las parroquias hasta que la Cédula del Rey Carlos III de 1787 indicó que estos se debían efectuar con algunos requerimientos específicos, que se cumplieron de manera errática, en virtud de la labilidad del poder político de esos tiempos.

Las condiciones de expulsión en algunos países europeos, sumado a la alta circulación comercial y productiva, fruto de las revoluciones industriales, llevaron Buenos Aires a conformarse como un lugar atractivo y controlado por pequeñas burguesías de origen extranjero.

En 1810 se logra pasar el río Salado, que divide el primer tercio de la provincia hacia el norte conformando una frontera marcada por atalayas y fuertes. Los pueblos que comienzan a fundarse hacia el interior de la llanura pampeana y parte del litoral poseen 
una conformación similar sobre la que se organizan: primero con una iglesia, una estafeta de correo y una pulpería, que era también un lugar de referencia e información (Djenderedjian, 2016).

La construcción institucional del Estado Nación argentino creció en forma paralela con las migraciones. Coincidimos con María Bjerg (2010) que desde 1830 la ciudad de Buenos Aires estuvo poblada no sólo por resabios de la colonia española sino también por portugueses, genoveses, vascos, irlandeses, escoceses, ingleses, franceses y alemanes, que además comienzan a adentrarse en la campaña bonaerense y el litoral, a través del comercio, el ferrocarril y la adquisición de tierras.

Después de la batalla de Caseros (1852), la situación cambió profundizando la idea desde la Constitución Nacional (1853) de que la migración era el elemento coadyuvante del progreso y el orden a medida que se conquistaban las tierras. En 1876, durante la presidencia de Avellaneda se sanciona la ley 817 de "Inmigración y colonización" que propiciaba negocios de traslado, asentamiento y gestiones con grupos poblacionales en proyectos particulares y privados variados, de relativo tenor, con éxitos fugaces.

Dentro de este contexto, las Asociaciones de Socorros Mutuos (en adelante ASM) surgen como lugares de encuentro al principio informales de los miembros de una nacionalidad que se organizan en la gran mayoría de pueblos y ciudades, a medida que arriba la migración, principalmente europea. Ese edificio asociativo, que empezaba pequeño, a veces en domicilios o negocios, y se iba ampliando con los años, era la representación de su nación en la sociedad de destino. Allí, el recién llegado podía pedir ayuda en cuestiones de salud, trabajo y vivienda a sus connacionales que, en virtud del capital social ya adquirido asistía (Bourdieu, 1987) siendo, además, refugio de la identidad idiomática, tradiciones y esquemas culturales.

Los clubes, romerías, ASM y las Sociedades de Beneficencia judías van a tener desde el principio de su conformación la necesidad de sepultar a sus fallecidos, aunque esto implicaba una erogación económica en un contexto en donde el espacio comienza a ser una mercancía en disputa. Esto plantea una capa de complejidad porque, como expresa Ariés (2000) los cementerios y el lugar para los muertos no son productivos, ni generan ganancias en un sentido material y al mismo tiempo, a fines del siglo XIX, serán atravesados por los discursos higienistas que gestionan los gobiernos y las políticas públicas (Trumpet y Griffiths, 2011).

Dentro de este complejo escenario es importante dar cuenta de un fenómeno que se constituyó como una gran huella mnémica en este período en donde la muerte tuvo un protagonismo inédito: la gran fiebre amarilla de 1871, que había tenido antecedentes años antes (Carbonetti, 2015; López Mato y Couto, 2015; Fiquepron, 2015). Esta peste que diezmó la población de Buenos Aires y dividió a la ciudad en un norte rico del sur pobre en donde se consideraba que estaba el foco de la enfermedad, constituyó un gran antecedente de que el Estado podía y debía ser el agente del control de la salubridad frente a la población hacinada. Se construyó el Cementerio del Oeste (hoy Chacarita) entre otros y se instruyó el cumplimiento de Reglamento Municipal de Cementerios, redactado por el Consejo Municipal de la Ciudad de Buenos Aires en 1868, que era "una intención común entre la política y la medicina pública, que perseguía el dominio de la muerte como instrumento institucionalizador" (Dal Castello, 2014). Es el momento en donde los rituales de despedida y de pasaje comienzan a ser trasladados a las casas velatorias y a los cementerios oficiales.

Será a partir de 1880 cuando el flujo cada vez más creciente de migrantes adquiere niveles impensados, llegando a una estimación de seis millones de arribados hasta 1914, con un saldo positivo de más de la mitad (Bjerg, 2010:19). Los gobiernos de 
la Generación del 80 tenían claro que el modelo agroexportador de materias primas era la matriz económica elegida, pero en cuanto a los aspectos políticos y sociales los problemas se profundizaban. En el marco de una sociedad cosmopolita y cada vez más compleja la pregunta que se hacía la élite gobernante a través de distintas disciplinas era ¿Cómo construir una identidad nacional? Porque dentro de la gran cantidad de arribos, llegaban italianos de la península recientemente unificada, de España que hablaban vasco o catalán, los franceses del sur, sirio-libaneses, rusos y otros grupos de gran heterogeneidad religiosa (maronitas, musulmanes, ortodoxos) y judíos europeos algunos de los cuales fueron acompañados por proyectos de colonización a través de la Jewish Colonization Association (Devoto, 2003:272).

En consecuencia, nos preguntamos si poder acceder a pensar en un cementerio o "embajada funeraria" propia o dentro de una necrópolis municipal y transformarlo de acuerdo a sus marcas identitarias era también considerado como un espacio de conquista y/o de resistencia de la propia ritualidad, dentro de una lucha por la búsqueda y edificación de una identidad argentina, por parte del Estado, que aspiraba a una homogeneidad.

La élite dirigente que gobierna la argentina entre 1880 y el Centenario conformó una ideología que Oscar Terán (2003) denomina "cultura científica". Esta subsume una forma de ver la vida social pasible de ser gobernada por leyes de las ciencias naturales y por un ordenamiento que se imponga desde la dirigencia a la "masa" babélica que seguía arribando. El positivismo, uno de sus matices, era conceptualizado como una cosmovisión que superaba el romanticismo y los aspectos religiosos (resabio de la colonia), abriendo un lugar a teorías fundadas en la biología, la psicología y las leyes naturales; aunque también operan represivamente a través de la Ley de Residencia (1902) y la Ley de Defensa Social (1910). Dentro de esta cosmovisión de la cultura científica el objetivo era nacionalizar y civilizar a los migrantes y en su defecto, a sus hijos. Para ello sancionaron la ley 1420, de Educación Común Gratuita y Obligatoria de 1884 y la del Servicio Militar Obligatorio 4301 de 1901. Carina Frid (1985 y 1988) estudió la campaña contra las escuelas de colectividades extranjeras que eran consideradas como un obstáculo para la integración, especialmente a las de las judías (atravesadas por el antisemitismo de las élites que lo asociaban con las corrientes de izquierda) y las italianas.

En las primeras décadas del siglo XX, como explica Devoto (2003:273) la mirada positivista de Ramos Mejía, uno de los más importantes exponentes del gobierno, se alejaba ya de un sueño idílico y rural de la migración como el remedio a todos los males latinoamericanos, para diagnosticar y evaluar qué se hacía con la "cuestión social". Los migrantes arribados se alejaban día a día de lo "imaginado" y de cómo deberían "haber sido": eran individuos que se agrupaban y resistían a través de hechos políticos, pero también dentro de espacios societarios que buscaban conservar la lengua, las costumbres y las tradiciones.

En su matriz ideológica, buscaban imponer una disciplina social que se aplicaba al individuo en sus aspectos más privados en los que quieren moldearlos, estableciendo tipologías de grupos con una importante raíz xenófoba. No quisiéramos extendernos en este tema, solo ilustrar la forma en que la mirada del funcionario de la generación del 80 se anclaba en la idea de que la pobreza y la miseria en la que se encontraba la gran mayoría de los arribados era una cuestión de voluntad o de genética en donde algunos de ellos nunca llegarían a "civilizarse". Como recupera Devoto (2003:288) de Ramos Mejía: "las observaciones llegaban incluso hasta la ceremonia en los entierros: nada de esos colores negros y demasiado relucientes en los "morenos enlutados", en la tapicería, en los sombreros, en los caballos "lujuriantes" que acompañaban la ahora popularizada pompa italiana".

De allí que, el derecho a ser enterrado con dignidad o "en cristiana sepultura" es un problema de integración al mismo tiempo que de segregación, que atraviesa discursos 
religiosos al mismo tiempo que políticos, en el marco de un territorio en disputa. Por esa razón, poder adquirir, conquistar, negociar o comprar un determinado espacio de tierra para enterrar a los muertos fue parte de la complejidad que tuvieron los distintos grupos migrantes.

\section{El acercamiento al campo}

El presente trabajo es un avance de una investigación a largo plazo que posee algunas particularidades metodológicas que es necesario explicitar. El recorrido se realiza de manera presencial, con una búsqueda previa de los sitios web, bibliografía e historiadores locales, a los que hemos recurrido en varias oportunidades; $y$ a fin de corroborar lo relevado acudimos a la Administración. Se procede a cubrir la nave central, la transversal y el perímetro, para luego transitarlo de manera más libre. Cada visita lleva en promedio una hora. Se registran los panteones, tumbas y placas de manera fotográfica, se mide el edificio funerario, anotando todos los detalles significativos.

El recorte de cementerios y espacios funerarios con identificación de nacionalidad como unidad de análisis toma en cuenta la ciudad más importante y receptora de migración de tres provincias (Buenos Aires, Santa Fe y Córdoba), de acuerdo a los núcleos estudiados por Julio Djenderedjian (2016) que describimos en el próximo párrafo y a toda la Ciudad de Buenos Aires, todo el conurbano y gran parte de la provincia de Buenos Aires que son los lugares en donde se ha asentado, en mayor medida, la migración histórica. Sobre estos nos hemos focalizado.

A fines del siglo XVIII, la mayor parte de la población se encontraba localizada en el interior cercano a Córdoba, Santiago del Estero y Tucumán; otro núcleo hacia Salta, Jujuy, Catamarca y La Rioja y por último Buenos Aires, Santa Fe, Entre Ríos y Corrientes; el resto estaba habitado por grupos de pueblos originarios y poblados escasos. Se ha dejado fuera de esta selección necrópolis también recorridas de Entre Ríos (Aldeas del Volga, Gualeguaychú), Chubut y Santa Cruz, para profundizar en estas vías específicas. Siguiendo a Devoto (2003:294-297) en 1914 uno de los elementos novedosos con respecto al censo anterior (1895) es la preferencia de los migrantes (57\%) por los espacios urbanos (Capital Federal, La Plata, Rosario y Córdoba y sus periferias). En ese mismo Censo se registra que el $29,9 \%$ de la población era extranjera. Los procedentes del Imperio Otomano, poseen otros patrones de inserción más vinculados al pequeño comercio de menudeo trashumante, asentándose en las cercanías de las estaciones del ferrocarril, llegando a La Rioja y Catamarca, quedando por consignar Tucumán, Santiago del Estero y La Rioja, donde también se localizó la migración árabe. Por esa razón, se concentró la observación en estas ciudades. Dentro de este relevamiento el margen de error que puede existir se basa en distintos factores, entre ellos el abandono, o la importancia que el municipio y la asociación le otorguen. Asimismo, en las últimas décadas los nuevos municipios que han construido cementerios, lo han hecho con una estética similar a los de tipo parque.

Se han relevado de manera presencial todas las necrópolis de la Ciudad de Buenos Aires (en lo sucesivo CABA) ( 5 cementerios), los 24 partidos del Conurbano bonaerense (39 cementerios), 84 partidos de la provincia de Buenos Aires ( 99 cementerios), Rosario (5 cementerios), Córdoba, capital y alrededores (12 cementerios) y San Fernando del Valle de Catamarca, capital y alrededores ( 5 cementerios), dando un total de 165 recorridos. ${ }^{2}$ El registro de los datos fue desde julio de 2013 hasta marzo de 2019, privilegiando las 
necrópolis municipales y los reconocidos por estas de otros credos. En el próximo punto expondremos los resultados obtenidos, donde acotaremos al mínimo las causas del asentamiento ya que excede el objetivo del presente trabajo, pero antes es importante dar cuenta de los aspectos en común que guardan los distintos cementerios y su ritualidad a fin de acercarnos a esta trasformación del espacio desde el concepto de heterotopía que "gana en poder explicativo cuando se emplea para definir instituciones de segregación o lugares donde se articulan políticas sociales, donde las tecnologías del poder son más visibles y donde los ideales de ordenamiento social son materialmente puestos en ejecución" (Cravino, 2014:36).

En este territorio recorrido se han identificado tres tipos de cementerios de los que se describirán brevemente los aspectos generales de su migración y conformación de los primeros enterratorios; asimismo, las regularidades morfológicas de su puesta performativa y, por último, un acercamiento a los ritos.

"Los cementerios de disidentes, fueron creados a partir de la prohibición de la Iglesia católica colonial de inhumar a los de otras religiones en sus camposantos (que por lo general hasta entrado el siglo XIX era en los alrededores y en las parroquias). Los grupos de comerciantes, navieros y estancieros de los clubes se agrupaban para comprar un terreno y así poder enterrar a sus connacionales. Se identifican por su variedad de cruces (especialmente de tipo celta), poseen escaza edificación sin resignar un compromiso artístico y de materiales donde predominan la piedra y los mármoles, así como una relación con la naturaleza que forma parte de su performatividad. Por lo general, también poseen epitafios en inglés, alemán, a veces en dialectos, este último a menudo con letras góticas, marcando un límite al foráneo. Poseen una capilla austera para recibir el cuerpo y efectuar una ceremonia. También disponen de un espacio de descanso llamado "Garden of remembrance" custodiado por figuras y flores ubicada estratégicamente, junto a un banco para el descanso de los visitantes. A menudo tienen espacios de conmemoración para los caídos en la Primera y Segunda Guerra Mundial. Las embajadas también son las que convocan a fechas patrias especiales. Estéticamente ofrece una puesta en escena en donde prevalece la tierra y los planos horizontales; en contraposición a los católicos que poseen edificaciones que buscan el cielo y una proyección de alineación vertical. (Figura 1)

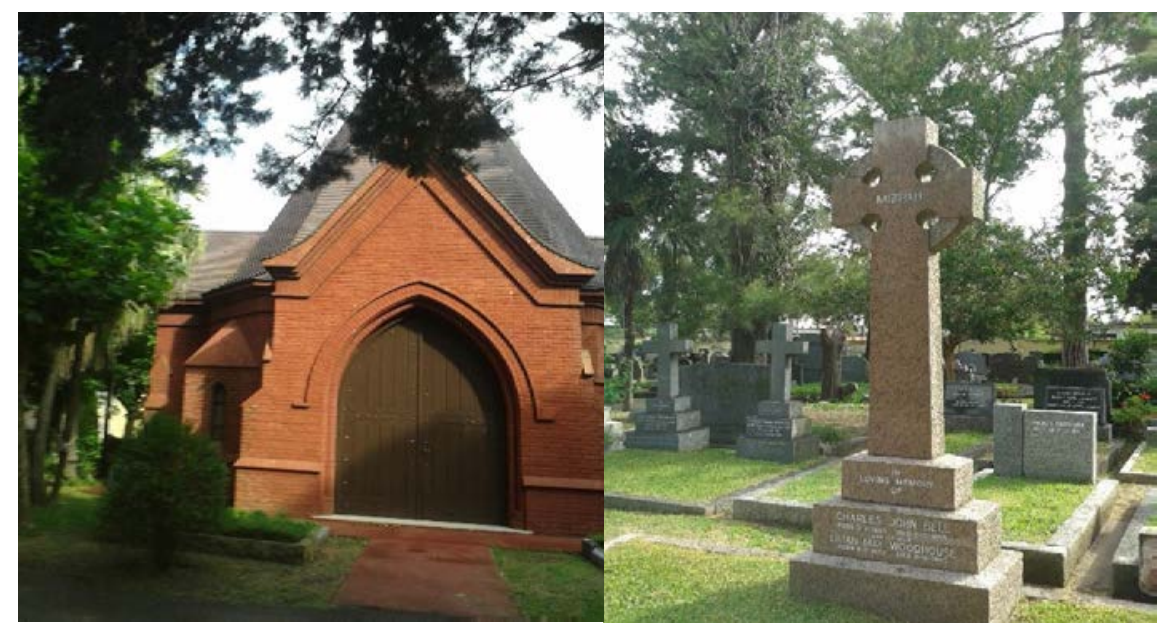

Figura 1. Cementerio de disidentes de Quilmes. Fuente: la autora, 2017.

» La Argentina tiene una de las mayores comunidades israelitas de Latinoamérica y la sexta fuera del Estado de Israel. Su arribo es muy antiguo, siendo las más tempranas 
las del siglo XVII cuando los judíos portugueses y españoles (sefaradíes) se asentaron trabajando como comerciantes y con oficios específicos, deviniendo -algunos-en trabajadores agrícolas. A mediados del siglo XIX se sumaron los de Europa occidental (ashkenazim) y en 1862, comenzaron a organizarse las primeras instituciones. Es muy importante su presencia en la zona del Litoral, donde fundan Moisesville y la colonia Arinsville, a la que se sumaron contingentes de Europa Oriental de la corriente ashkenazim. A través de la Jewish Colonization Association, la afluencia creció a fines del XIX y a partir de 1930 especialmente en los que provenían de Alemania y ya contaban con una importante comunidad de base (Dulout, 2011). A pesar de su antigüedad, logran recién a principios de siglo sus propios espacios de enterramiento, a través de la compra o donación de tierras. Estos requerían una administración propia en virtud de poseer días de visita y celebraciones que no eran las oficiales.

La tradición considera que la inhumación ideal sea en la patria y junto a sus familiares, pero con la diáspora, los mitos ancestrales han sufrido modificaciones en los detalles, no en la importancia dispensada o el respeto al rito.

Existe un tema importante en función de "que la religión judía prohíbe la representación de Dios o cualquier símbolo que lo represente, la fuerza simbólica de los monumentos está volcada en la propia estructura. Son los casos del monumento por la Shoa" (Dulout, 2011) y otros que marcan situaciones colectivas que tienen una celebración anual con todos los miembros de la comunidad.

La modalidad es la sepultura en tierra -ya que es indispensable que el cuerpo esté en contacto con ella-lo cual contradice las normativas municipales que prohíben la inhumación sin ataúd; finalmente se llegó a un acuerdo con orificios en los féretros que permiten cumplir con ambos. Usualmente se esparce un puñado de tierra traído de Israel y se paran en dos filas a través de las cuales el pariente más próximo sale primero del cementerio. El cuidado del cadáver es parte de la tarea religiosa de carácter sagrado a partir de un subgrupo que toda institución posee, que envuelve al fallecido en una mortaja blanca de algodón. El cuerpo debe ser enterrado lo más pronto posible para cumplir con los preceptos bíblicos. El funeral se realiza de manera sencilla, sin flores ni música, predominando el ataúd en madera simple y sin adornos (Dulout, 2011). Toda persona que ingrese debe tener la cabeza cubierta en señal de respeto.

Otra particularidad es que los restos no pueden ser reducidos, porque el lugar de descanso es eterno y no puede modificarse, lo cual lleva a que inevitablemente los cementerios deben ampliarse o crearse nuevos.

Existe un aspecto importante, expresado claramente por la AMIA en su página web acerca de los procedimientos para inhumar el cuerpo, de acuerdo a un estudio de la Biblia y el Código de Leyes Judío:

Existe una prohibición concreta sobre la inhumación de una persona de origen judío con otra, que pertenece a otro pueblo. El entierro tradicional judío junto a sus antepasados, le da al alma del fallecido un gran consuelo, y le provee la transición necesaria para ingresar a un mundo completamente espiritual. A su vez, origina un beneficio para el cuerpo y el alma del difunto, permitiéndole su eterno descanso con sus ancestros, de acuerdo a los ritos y mandamientos de la milenaria religión judía. Por otro lado, el entierro en un cementerio no comunitario, le causa al alma del difunto un gran perjuicio, evitándole retornar gentilmente a Dios. (AMIA, 2018)

Según el Superior Rabinato de la República Argentina no se puede concurrir en shabat y su víspera desde las 13 hs. Según este órgano religioso, la muerte une al individuo con un largo entramado de sentido comunitario: "El cementerio es uno de los máximos 
símbolos de recordación que contribuye al agrupamiento familiar más allá de la vida, es el protagonismo de la historia."

Los cementerios israelitas poseen algunos elementos en común: su cerco perimetral es alto y con portones que no dejan ver el interior. Tienen una regularidad estética y las tumbas pueden tener un monumento funerario, por lo general de mármol negro, en donde los visitantes acostumbran poner una piedra sobre la superficie de la tumba, los domingos. En algunos hay recipientes con piedras a fin de cumplir con el rito (Flores y Dulout, 2006) (Figura 2).

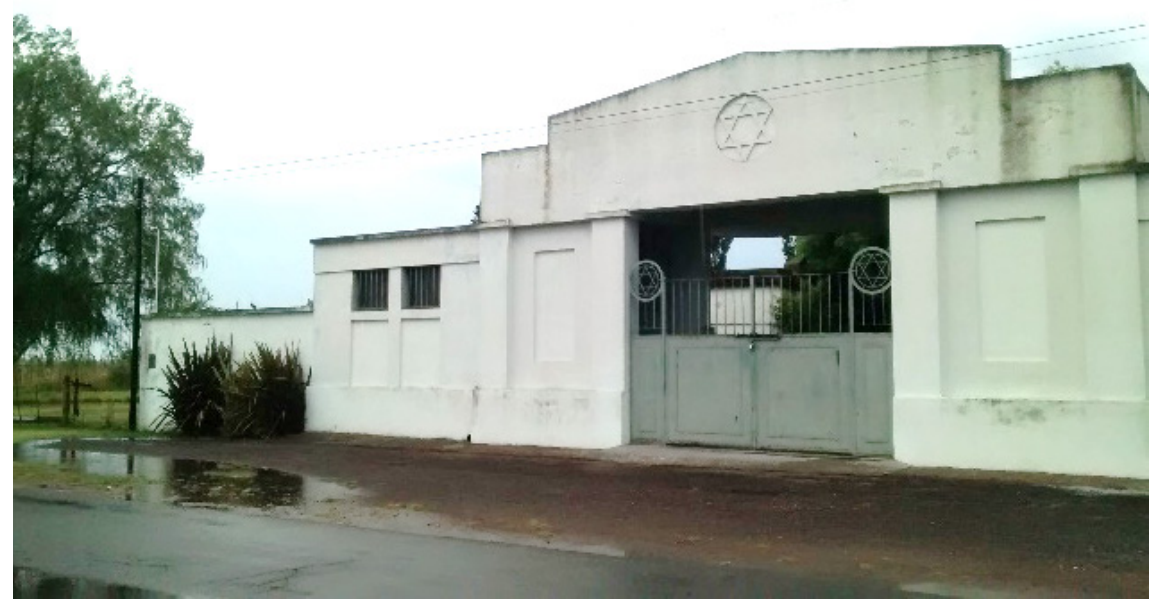

Figura 2. Cementerio judío de Carlos Casares. Fuente: la autora, 2018.

Por último, agrupamos a c) los edificios de Asociaciones de Socorros Mutuos, que compraban un espacio dentro de los cementerios administrados por las municipalidades, que estaban bajo el credo católico apostólico romano y bendecido por los prelados del lugar. Dentro de estos cementerios prevalecen tres tipos de construcciones: 1) los panteones son como pequeñas iglesias que pueden ser como una casa pequeña hasta edificaciones de gran valor artístico en donde intervinieron arquitectos famosos y maestros de oficios (especializados en vidrios, esculturas, herrería y ornamentos); 2) las nicheras (se sitúan especialmente contra las paredes perimetrales, pero también se encuentran independientes: son edificaciones simples, en forma de cajoneras, donde se coloca el ataúd de manera horizontal y se sella la puerta, con el número y la identificación. Estas son muy utilizadas por las ASM una vez que el panteón originario se completa, construyendo una serie de "sucursales" en el mismo cementerio, con un costo más bajo que el primero. Por último, se encuentran 3) las áreas de tierra, que es el espacio más barato para el enterramiento, a menudo cercado o identificado con una placa. Hasta el momento hemos registrado dos en donde se dejan coronas y en algunos casos, se entierra la urna de cenizas. Un subgrupo de esta categoría y que se ha registrado en los cementerios es un lugar en la entrada de los mismos para la ubicación de placas instalada en los distintos aniversarios. Las ASM han construido panteones y nicheras que se considerarán de igual manera en virtud de la gran variedad de edificaciones que hemos relevado donde hay algunos pequeños y simples, así como nicheras de gran presencia e importante contenido simbólico y material. Se han registrado en su mayoría de asociaciones italianas, españolas, francesas, sirio-libanesas y unas pocas de otras nacionalidades (Figuras 3 y 4). Hemos registrado en CABA, en Recoleta, un panteón de ASM portuguesa, en Chacarita de una uruguaya, eslovena y yugoeslava, en Zárate provincia de Buenos Aires, uno austrohúngaro (abandonado), en Córdoba uno japonés y otro de la Sociedad Católica Apostólica Ortodoxa y en Rosario de "orientales" de los que no hemos podido recabar más datos aún. 


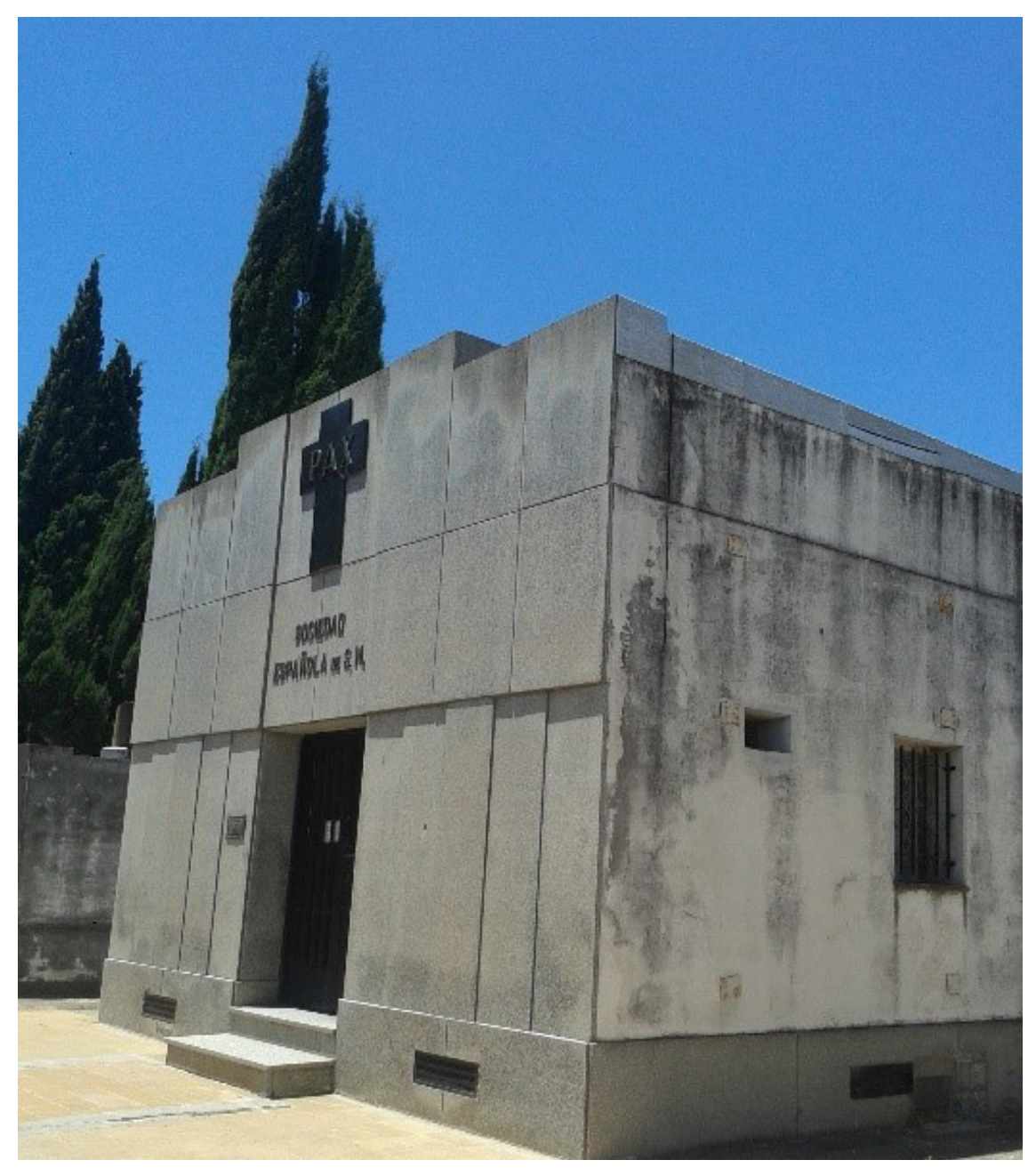

Figura 3. Panteón de la Asociación Española de Socorros Mutuos de Zárate. Fuente: la autora, 2018.

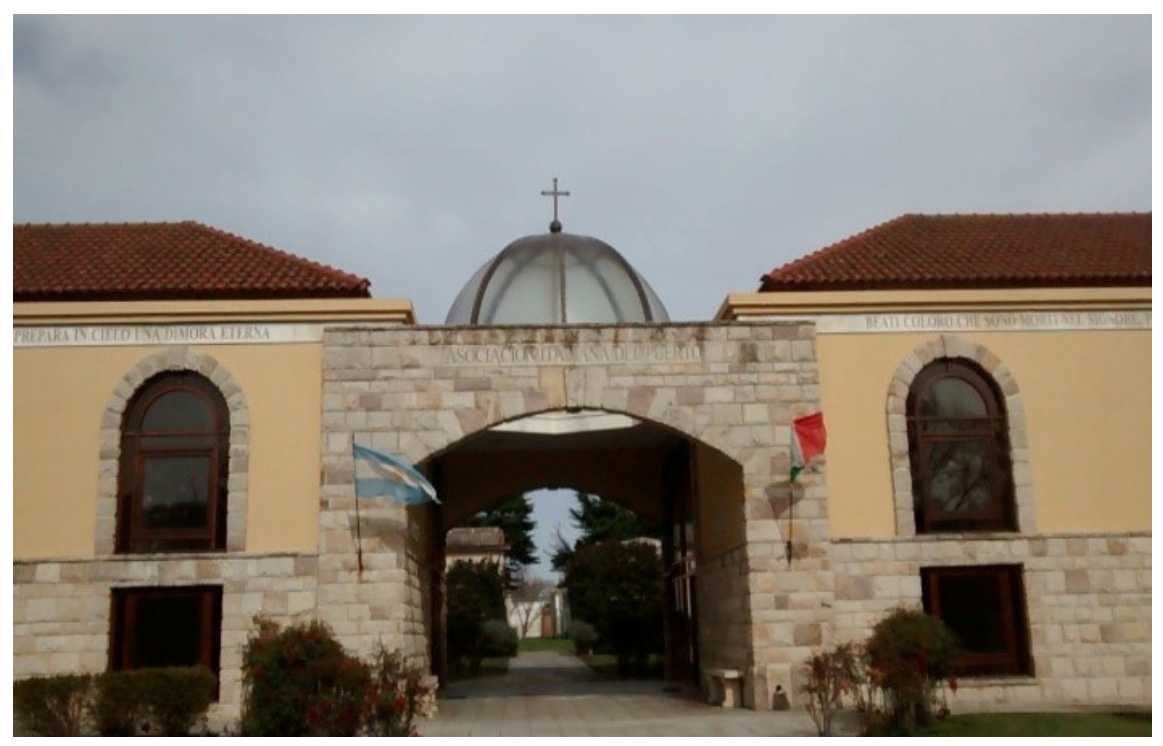

Figura 4. Panteón de la Asociación Italiana del Puerto. Fuente: la autora, 2018. 
En la CABA, (ex Ciudad de Buenos Aires y ex Capital Federal), existen enterratorios en las cercanías de la Plaza de Mayo y alrededor de las iglesias parroquiales. En 1822 Bernardino Rivadavia ordenó la formalización de uno junto al Convento de los Recoletos, conformándose en el primero oficial y que luego se transformó en uno de los más famosos por su composición estética y el nivel artístico de sus panteones y bóvedas familiares. (Figura 5)

Los de Disidentes corrieron una suerte más itinerante. Como se ha descubierto recientemente, el primer cementerio fue en la actual Plaza $1^{\circ}$ de Mayo en el barrio de Balvanera, hasta que un comerciante próspero en 1817 reúne aportes de la comunidad a fin de solicitarle al Gobernador Martín Rodríguez la compra de un espacio que finalmente se concreta en 1821 bajo el nombre "Corporación del Cementerio Inglés", cercano a la iglesia del Socorro. Unos años después, la ampliación fue denegada, consiguiendo otro terreno al que llamaron "Victoria" en honor a la reina ${ }^{3}$. A partir de la Fiebre de 1871, fue construido el Cementerio del Oeste (usualmente llamado Chacarita), a fin de enterrar a los fallecidos por la epidemia, permitiéndose que en un sector delimitado como "no católico", se inhumaran a los protestantes y judíos. En 1891 se llegó a un convenio con la Municipalidad de la Ciudad de Buenos Aires que le otorgaba a perpetuidad a la Congregación de Disidentes Extranjeros la sección XVI del cementerio de la Chacarita, separado por un muro. En la Primera Guerra Mundial, en virtud de que la mayoría era británica y alemana, alzaron una pared separándose, hasta 2018, cuando abrieron una puerta en el $100^{\circ}$ aniversario del fin de la guerra, con representantes de ambos países y la presencia de la comunidades y descendientes.

A partir de 1825, el Rey Jorge IV de Inglaterra reconoce la nueva Nación de Buenos Aires y firma el Tratado de Amistad y Comercio. Si bien no numerosa, la comunidad anglosajona fue muy influyente y significativa durante el siglo XIX. Había ampliado su capacidad comercial y desarrollaba las bases del Ferrocarril del Sud, que a partir del 1880 crece de manera expansiva, requiriendo de un importante despliegue de entidades financieras, oficinas de negocios y bancos que operaran en función del modelo agroexportador que imperó desde 1880 a 1930, decreciendo significativamente como el resto de los flujos a partir de $1914 .^{4}$

El barrio de Flores fue fundado en 1827 y formaba parte del "camino de los reinos de arriba”, parada obligada antes de Luján, vía Potosí. Fue atravesado tempranamente por los símbolos de progreso que a través de la calle Rivadavia, comenzaron a bordearlo: en 1857 llega el ferrocarril y en 1871 el tranvía, cerca de la plaza, la estación y la iglesia (Maronese, 2006). El pueblo se colmó de fondas, casas de ramos generales, talabarterías, herrerías y boticas, conformándose en un barrio de migrantes, por su rápido acceso al resto de la ciudad. Su cementerio se bendice en 1832. En el presente, el 2 de noviembre se congrega la comunidad boliviana de la ciudad a celebrar el "Día de los muertos" en virtud de que gran parte de su colectividad se encuentra enterrada allí. Desde hace más de una década cada 2 de noviembre desde la mañana concurren migrantes limítrofes a honrar a sus muertos, rezar y llevarles los alimentos, las bebidas y los objetos que le gustaban al fallecido. También se contratan bandas musicales. Es importante destacar que esta festividad se realiza con un importante control de la policía de la CABA. 
Existe un predominio de terreno para tumbas en tierra y es considerado como el "cementerio de los pobres", así como el de Chacarita de clase media y el de Recoleta, de los ricos. Pero, como se evidencia en el Anexo, existe una importante presencia de representación de panteones migrantes en el cementerio de la Chacarita (19), dos en la Recoleta y dos en Flores, además de cementerios anglosajones, y una ausencia de los judíos que, que por diversos motivos (económicos, diversidad de orígenes, etc.) entierran a sus muertos, primero en Chacarita y luego en Flores hasta que en 1910 compran los terrenos en Liniers.

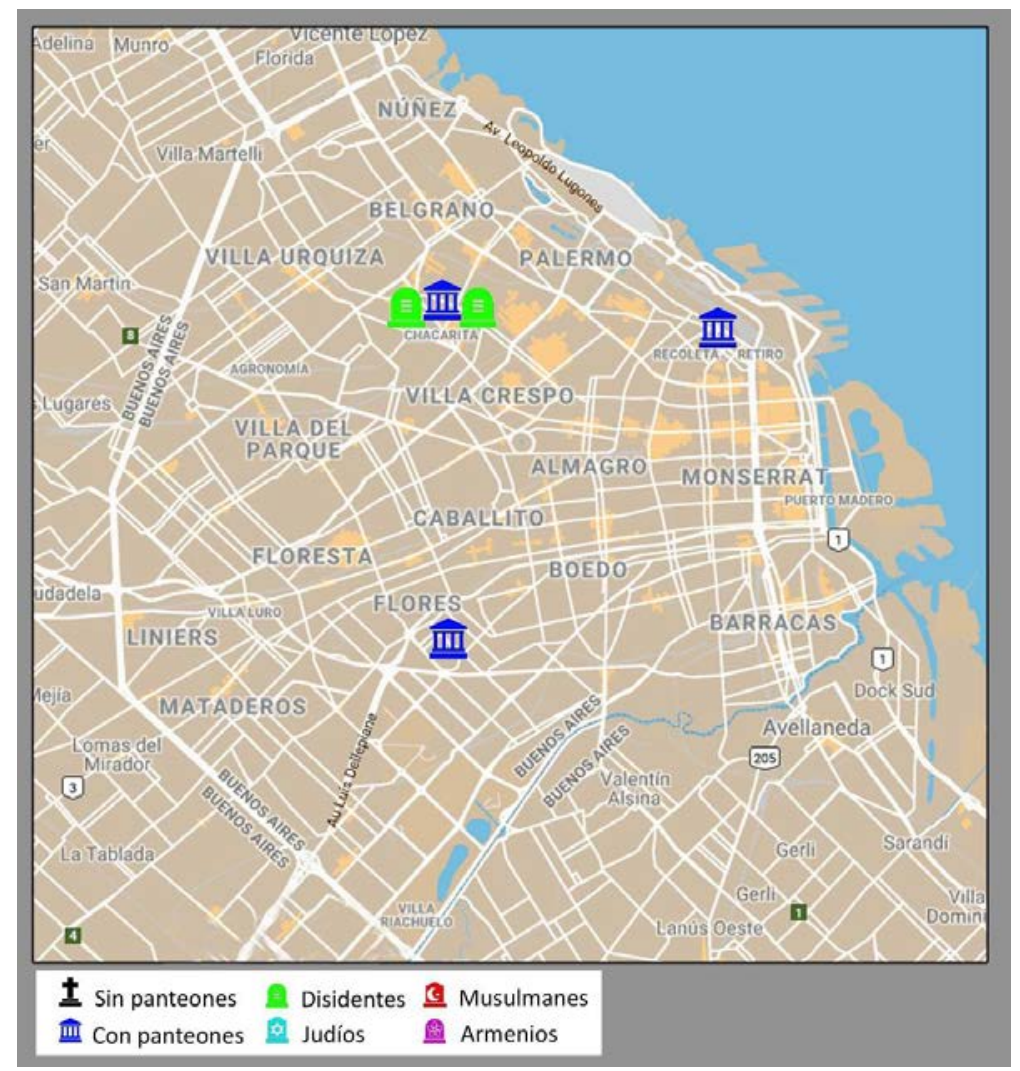

Figura 5. Cementerios de la CABA. Fuente: Elaboración propia, sobre base de Gmaps, 2019.

El Conurbano bonaerense es un conjunto de 24 partidos que rodean la CABA. Gran parte de estos municipios se fundaron a partir de pueblos devenidos en ciudades por el aumento de su población, no solo nativa sino también de migrantes que luego de las guerras nutrieron las existentes. También se asentaron las migraciones internas que encontraban oportunidades laborales y de viviendas más baratas que en CABA, con una importante conexión de medios de transporte.

Algunos de estos partidos son de reciente formación por el desmembramiento de otros más grandes, especialmente bajo una gran reforma realizada en 1994, siendo los municipios más antiguos lo que tienen más proporción de cementerios y panteones de origen migrante (Figura 6).

En el cementerio judío de La Tablada, en La Matanza, cuentan con monumentos en memoria a los caídos por la defensa del Estado de Israel, víctimas del Holocausto (con cenizas de los campos de exterminio en su interior), por el atentado a la Embajada de Israel, a la AMIA, y en memoria de las víctimas de la última dictadura militar. Existen otros espacios de visita en conmemoración a los mártires judíos de Galitzia "Polonia" y judíos de habla húngara en la Argentina. También cuenta con monumentos artísticos conmemorativos. 


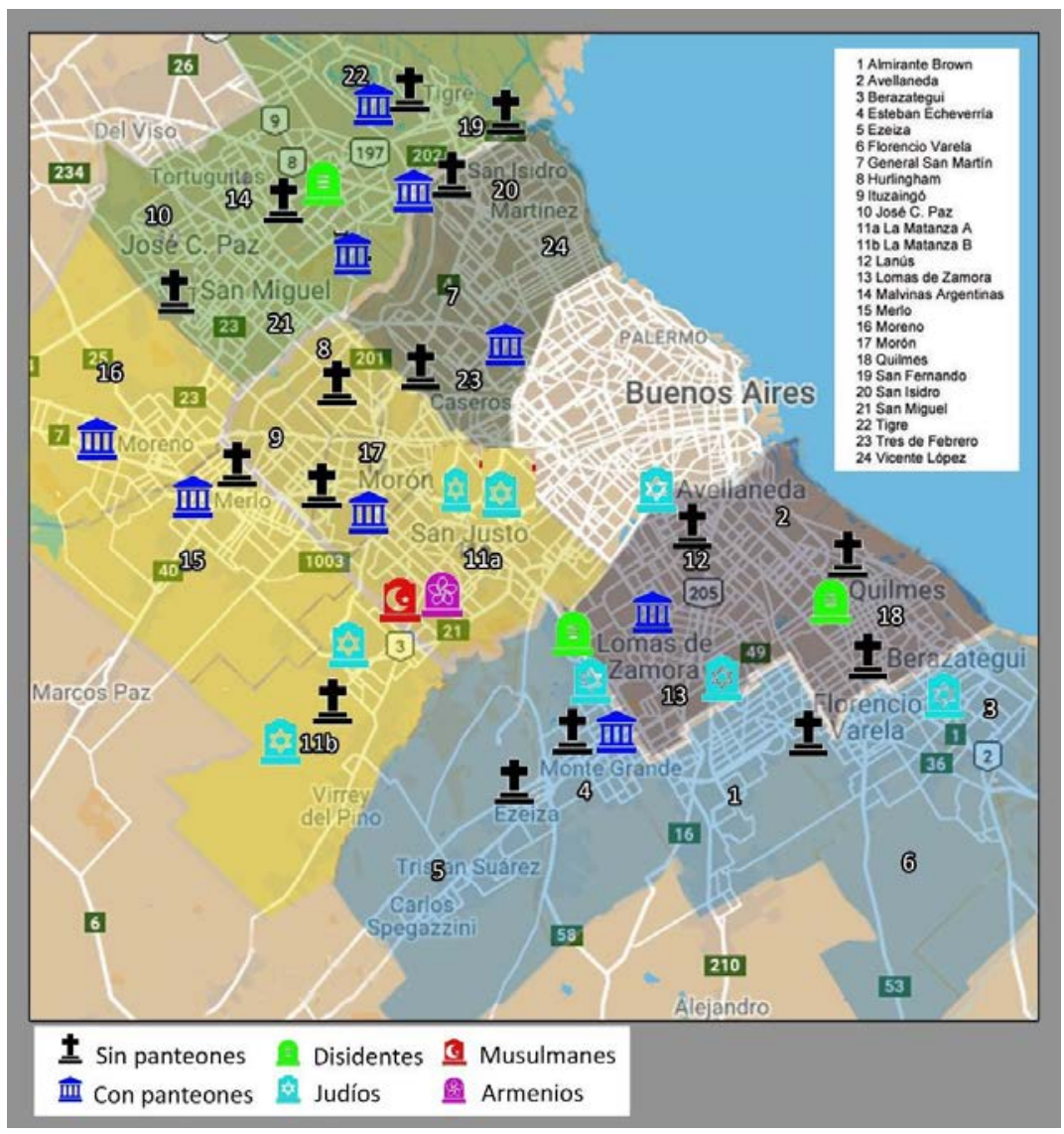

Figura 6. Cementerios de los partidos del Conurbano. Fuente: Elaboración propia, sobre base de Gmaps, 2019.

Asimismo, en un extremo del terreno, hay un espacio destinado al Cementerio Israelita sefaradí de la Asociación Hebrea Argentina de Socorros Mutuos, fundada en 1929.

Los cementerios de Lomas de Zamora son de la Asociación Israelita Sefaradí Hijos de la Verdad adquirido en 1913 e inaugurado en 1915 por la Sociedad de Socorros Mutuos Benei Emet, para judíos sirios de Damasco y el Cementerio Israelita administrado por la Sociedad Dr. Herzl, para los ashkenazim.

El cementerio de Avellaneda tiene una historia compleja que se origina cuando una parte de migrantes judíos se hizo rico vertiginosamente, dejando perplejos a los que se dedicaban a la agricultura y el comercio. Al poco tiempo, se conoció que eran los "tratantes de blancas" que traían engañadas a mujeres de origen judío que explotaban en la zona sur de la capital. Ese grupo pasó a llamarse los “ $\mathrm{T}$ ' mein" (impuros en idish). Al ser rechazados decidieron tener sus propias organizaciones, sinagoga, rabinos y cementerio, adquiriendo los terrenos al otro lado de la calle del Cementerio Municipal de Barracas al Sur, hoy Avellaneda.

Los cementerios de disidentes de la actual Malvinas Argentinas, Lomas de Zamora y Quilmes, se relacionan con el ferrocarril y pequeños emprendimientos industriales (cerveza, por ejemplo), en barrios donde residía la comunidad que fundaba sus clubes, hogares de ancianos y eventualmente compraba o donaba un terreno para sus connacionales.

Los cementerios con panteones de ASM se asientan en las ciudades más antiguas, nutridas por las diferentes corrientes migratorias, favorecidas por la cercanía con la CABA a través de ferrocarril, y las facilidades del transporte que les permitía trabajar en la ciudad y residir en el conurbano. 
La provincia de Buenos Aires presenta una importante heterogeneidad con cementerios que fueron espacios de enterratorios que se remontan a la colonia y a las sucesivas campañas de exterminio de los pueblos originarios y fundación de pueblos hasta otros de reciente formación.

Como se observa en el mapa (Figura 7), la presencia de panteones de origen étnico es sumamente significativa y se distribuyen de manera importante en el territorio. Como hemos mencionado al principio, las ASM se constituyeron tratando de cubrir necesidades de los migrantes en el marco de un contexto difícil. Las dificultades del Estado en formación, la crisis económica de 1890, el trabajo vinculado a las necesidades de un modelo y un clima ideológico en donde como expresa Devoto (2003:271) "se trataba de convertir a aquellos extranjeros en argentinos, no sólo desde el punto de vista jurídico sino desde el cultural", hicieron que gran parte de estos espacios de socialización se transformaran también en lugares de conservación y resistencia identitaria. No todas las ASM destinaban su capital a la construcción de panteones étnicos (por decisiones de la Comisión Directiva del momento, emergencias y necesidades de la sociedad de origen con las que contribuían, cuestiones ideológicas, religiosas, económicas, etc.), de manera que su presencia resulta sumamente significativa.

En el estudio sobre las Actas de la Asociación Española de Socorros Mutuos de Rosario (Castiglione, 2017), relevamos las discusiones que se dieron en función de la construcción del panteón en donde un grupo alegaba que había que cuidar "de los vivos", ya que el capital era limitado, mientras que otro argumentaba que el cuidado del socio era también "darle cristiana sepultura", cuidándolo aún después de fallecido. En otro trabajo, con respecto a la Asociación Española de Socorros Mutuos de Belgrano (Castiglione, 2016) siguiendo la misma metodología, encontramos que, para esta asociación, además del compromiso identitario y que era parte del servicio que ofrecía, ya que su panteón se encontraba cercano (en La Chacarita), era también parte de su capital monetario, de la inversión y del crecimiento.

Asimismo, como se puede observar en el Anexo, en algunos cementerios se encuentran hasta siete panteones evidenciando no sólo la importancia y el peso de esa ASM, sino que a veces cubrían espacios que excedían al partido geográficamente delimitado, conformando lazos densos de relaciones e influencias.

Dentro de este escenario de recepción, también hubo una corriente, de ruso-alemanes, más conocidos como Alemanes del Volga que desembarcaron en 1877, para trabajar en el campo a través de la Ley Avellaneda de 1876. La primera colonia que se estableció fue en Hinojo a quince kilómetros de Olavarría al centro de la provincia de Buenos Aires, fundada por ocho familias y tres solteros.

En Azul, el espacio de disidentes se encuentra en un costado rectangular amurallado de $250 \times 8 \mathrm{~m}$, al que se ingresa atravesando el cementerio principal. En el Libro de actas Municipal No 3 que registra desde los años 1879 al 1883, se relevó que, en la sesión del 16 de abril de 1880, se requiere el acondicionamiento de un predio para ser utilizado como cementerio "no católico" (Adam, Eilers y Carrasqueño, 2013). No hay panteones, sólo lápidas, losas de mármol o granito y rejas artísticas que bordean algunas tumbas. También se encuentran lápidas escritas en general en inglés y alemán. Estas particularidades son comunes a los otros cementerios de disidentes de Quilmes, Lomas de Zamora (en el Gran Buenos Aires), Chascomús y Castelli.

En Baradero, dentro del cementerio, pero separado hay un espacio de la colectividad suiza, de una corriente arribada en 1856, procedente del cantón de Friburgo, no muy numerosos y con capital para invertir en tierra y ganado lechero, destinada a las colonias entrerrianas, pero luego asentada en el norte de la provincia de Buenos Aires. 
La migración danesa de Tandil, fue estudiada por Devoto (2003) como un ejemplo de las cadenas migratorias identificadas como de origen familiar y cadenas más amplias sobre base lugareña. De ésta última proceden los daneses del distrito de Magleby en la isla de Møn, Dinamarca, de 1.500 habitantes. Esta migración incluyó no sólo a familiares sino también a amigos y simples conocidos, iniciada por un pionero, Juan Fugl, maestro de escuela que emprende el viaje en 1844.

La monarquía danesa había desarrollado una serie de reformas restrictivas de acceso a la tierra y confirmaron viejos sistemas de herencia, de manera que los jóvenes comenzaron a buscar nuevos destinos. Si bien se estima que el número de daneses emigrados es cerca de 6.500, su presencia en Tandil no fue voluminosa, pero sí heterogénea e intensa. Influyeron tanto en el espacio urbano como en el rural, casi por igual (Bjerg, 2001). Fugl, al poco tiempo de haber arrendado una chacra, instaló un molino hidráulico, una panadería y se insertó políticamente llegando a ser intendente de la ciudad. Su importante rol dentro de la sociedad tandilense les facilitó el espacio dentro del cementerio municipal en un terreno cercano a la puerta principal, de forma rectangular de $5 \mathrm{~m}$ de frente por $50 \mathrm{~m}$ de largo, siendo uno de sus segmentos más largos bordeado de coníferas. Sus tumbas son rápidamente identificadas por la uniformidad cromática en colores oscuros y piedra, un obelisco y una cadena que los separa del resto. Las inscripciones son en danés y se observan cruces que no se registraron en ningún otro cementerio, como la cristiana inclinada sobre la izquierda.

Este cementerio además posee una importante presencia de panteones españoles e italianos de distintas épocas, ubicados en lugares importantes e imponentes por su magnitud.

El Cementerio judío de Carlos Casares se originó a partir de la empresa colonizadora del Barón Mauricio Hirsch, que gestionó el arribo de judíos que huían del régimen zarista, fundando colonias especialmente en Entre Ríos y Santa Fe, pero también en Buenos Aires como esta, la Colonia Mauricio, que nació a partir de 1500 familias.

El espacio dentro del Cementerio de Mercedes, cuenta con una pequeña edificación destinado a la Sociedad Israelita Latina de Mercedes fundado el 9 iyar 5688 (29 de abril de 1928), por el Sr. Jacobo Sananes. Posee una pequeña construcción y un cuarto de $2 \times 3 \mathrm{~m}$, con un camastro, para el tratamiento del cuerpo y preparativos. En este se registra los dos rasgos identitarios de recreación constante, como el idioma hebreo y el calendario. Nos resulta curioso porque no hemos encontrado referencias de una actividad judía específica en esa región, más que las generales de comercios en las cercanías de estaciones ferroviarias.

El Cementerio de La Plata nace a partir de la "Sociedad de Socorros Mutuos Ezrah" en cuyas primeras reuniones (1907), surgió la necesidad de un cementerio local, como una prioridad. En esos tiempos, las necesidades eran muchas y variadas, de manera que logran finalmente adquirir una escritura que la Municipalidad de La Plata les regala para la construcción del cementerio el 9 de noviembre de 1913, cuando realizan una ceremonia en la que trasladan los restos de asociados, quedando oficialmente inaugurado.

Por último, el Cementerio israelita de Gral. Pueyrredón, donde se encuentra la ciudad de Mar del Plata es relativamente reciente (1968), y su proyecto de construcción ha sido premiado por su diseño vanguardista (Arteabaro, 2018). 


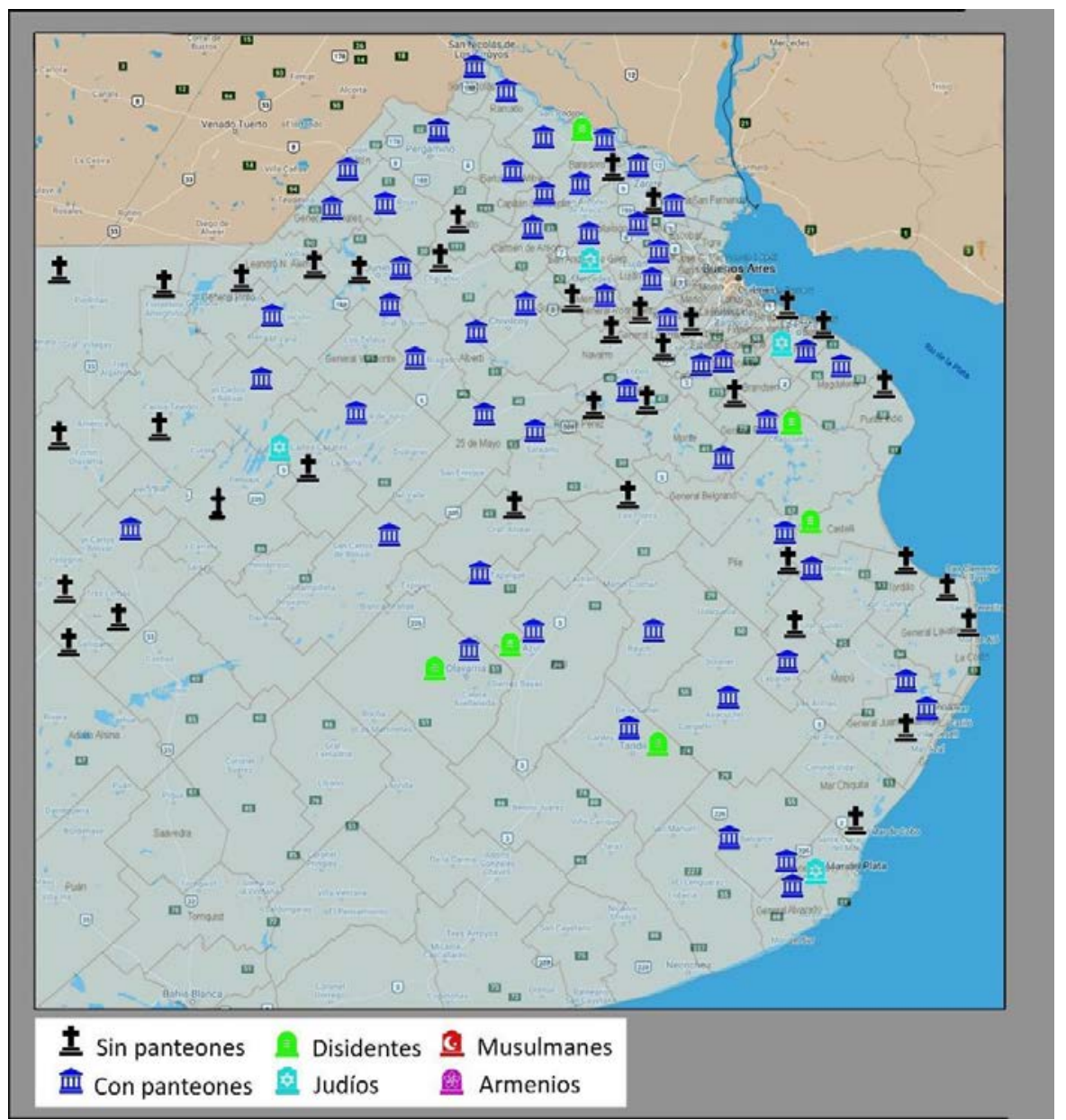

Figura 7. Cementerios de la Provincia de Buenos Aires. Fuente: Elaboración propia, sobre base de Gmaps, 2019.

La ciudad de Rosario, si bien no es la capital provincial fue un destino de importante radicación migratoria en virtud del puerto fluvial. La importante presencia de trabajadores, al principio como jornaleros, y luego como pequeños comerciantes constituyeron un núcleo de italianos y españoles que dinamizaron la economía del sur de Santa Fe, estableciéndose a partir de los bajos costos de las tierras y cédulas hipotecarias, así como de la expansión del ferrocarril (Frid, 2006). Un temprano asociacionismo proveyó de información y ventajas desarrollando un amplio marco de actividades que iban desde el menudeo hasta la presencia de grandes firmas navieras, bancarias y empresariales (Fernández, 2006) (Figura 8).

Sus cementerios y panteones reproducen la movilidad social de los grupos migrantes tanto en la necrópolis del "El Salvador" como el de "La Piedad" evidenciando el ascenso de una burguesía emergente y cosmopolita (Giménez y Solá, 2018)

Como ciudad próspera a fines del siglo XIX, también migraron judíos ashkenazís que fundaron en 1903, la Asociación Israelita de Beneficencia conocida como "Kehilá", (comunidad), que cuenta con hogares de ancianos, escuelas, sinagogas y los dos cementerios (el viejo y el nuevo).

Dentro de este entramado económico en ascenso, los comerciantes ingleses, alemanes, suizos y norteamericanos, también migraron hacia esta ciudad, consiguiendo un espacio al que llamaron Cementerio Protestante y luego Cementerio de Disidentes. Una de las características distintivas, es que allí se encuentran enterradas seis maestras norteamericanas, de las 65 que trajo Sarmiento, para educar y "civilizar" a la población local. 


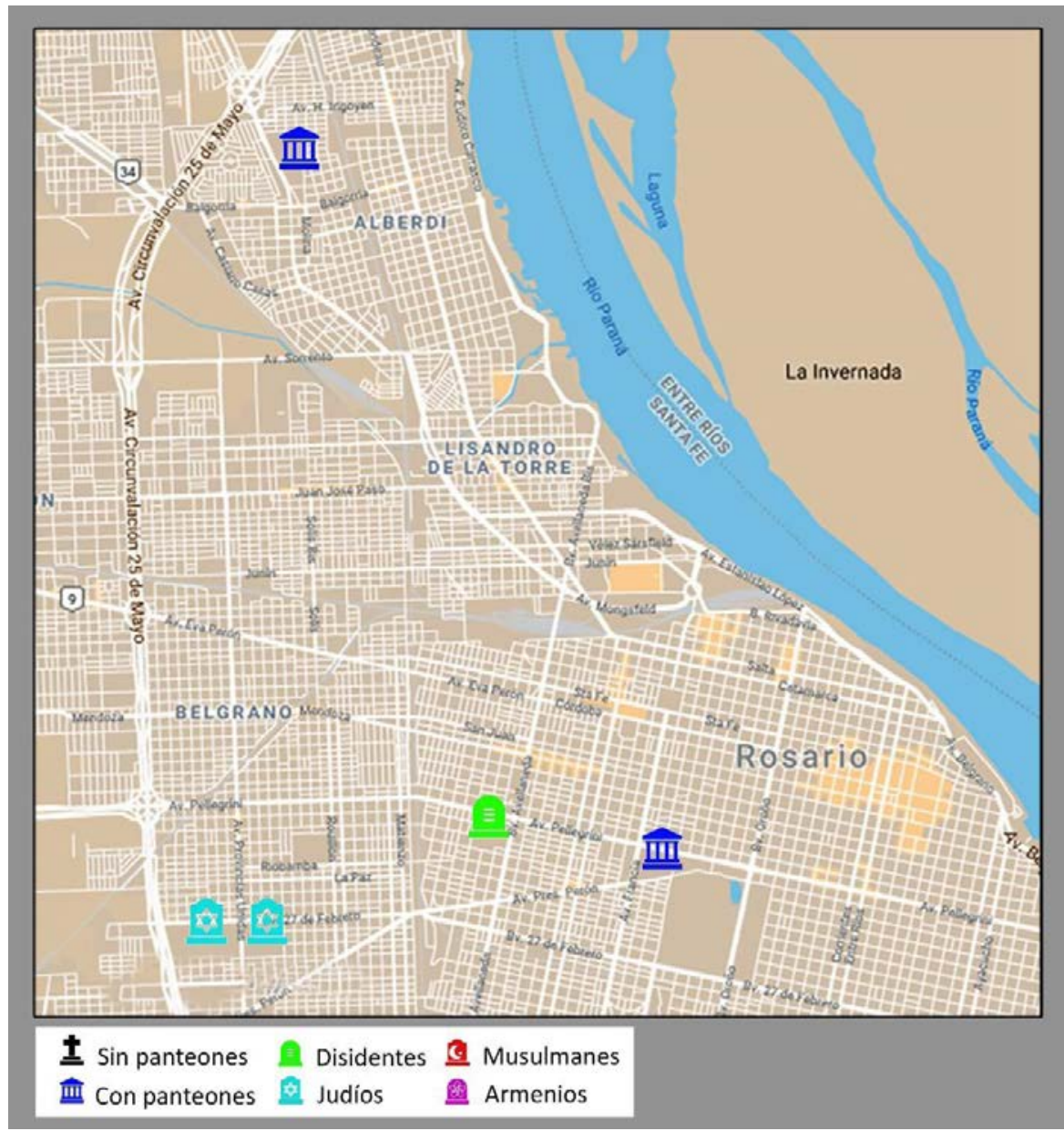

Figura 8. Cementerios de Rosario, provincia de Santa Fe. Fuente: Elaboración propia, sobre base de Gmaps, 2019.

Córdoba como capital provincial, posee una historia profunda y antigua que excede el presente trabajo, vinculada al Camino Real del Alto Perú, fundada en 1573. La presencia de migrantes de fines del siglo XIX y principios del XX registran un $61 \%$ de italianos en áreas rurales, como parte de las recorridas --entre ellas Colonia Caroya--, y la misma proporción, pero en las ciudades, de españoles de acuerdo al Censo de 1914 y que como expresa Devoto da "una foto del conjunto". (Figura 9)

Dentro de este cosmopolitismo encontramos el único panteón de japoneses en el cementerio de San Vicente, que en la misma cuadra linda con cementerio musulmán y el judío de la década del ' 20.

La presencia de panteones de ASM (italianos, españoles y franceses) es importante y da cuenta de diversos grupos y corrientes que retroalimentaron de manera constante su importancia como ciudad en el dinamismo económico y político. Su universidad fundada en 1767 por los jesuitas, fue cuna de la Reforma Universitaria de 1918 que amplió los derechos para los hijos de migrantes y de las clases medias, siendo también un espacio importante para los exiliados de la Guerra Civil española (1936-1939) e intelectuales de la época.

Como se puede observar, en ambas ciudades provinciales, se encuentran cementerios con una importante historia no solo de los panteones étnicos, sino también de otros grupos migrantes de origen heterogéneo, que se desplazaron a estos centros económicos, asentándose. 
Dentro de la migración de la segunda posguerra, en el sur de la provincia (Villa General Belgrano, Calamuchita) arribaron un grupo de migrantes centroeuropeos (alemanes, suizos, húngaros y austríacos), que intentaron conformar una colonia agrícola autoabastecida, que devino con el tiempo en un centro turístico de productos alemanes a través de festividades de cerveza, chocolate y souvenirs, que persiste hasta el día de hoy. Escondido en la sierra se encuentra un pequeño cementerio propio de la comunidad alemana y sus descendientes que permanece oculto al público por haber sufrido profanaciones y actos de vandalismo.

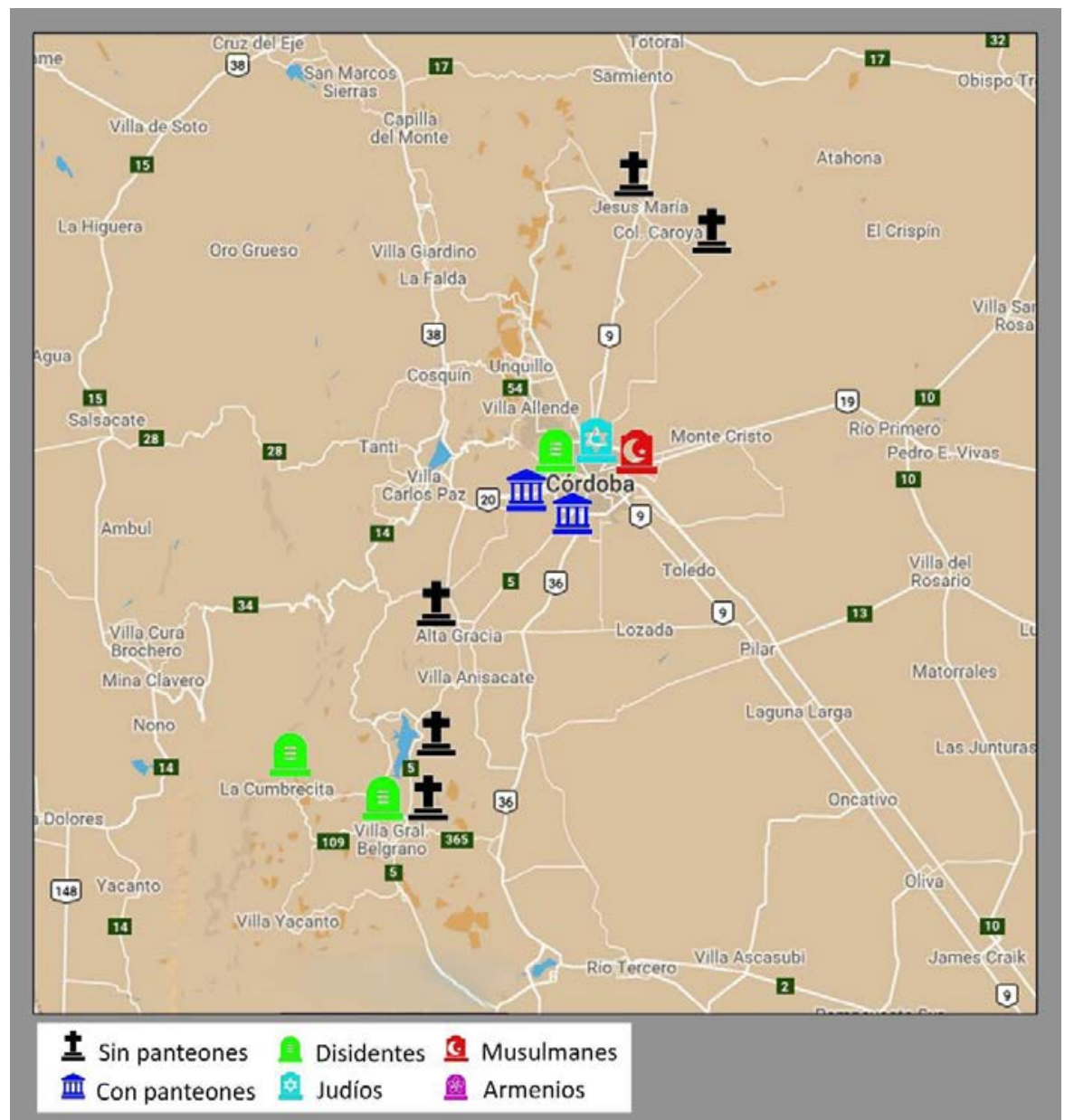

Figura 9. Cementerios de Córdoba y alrededores. Fuente: Elaboración propia, sobre base de Gmaps, 2019.

Las características geográficas y climáticas de Catamarca (Figura 10) se encuentran presentes en las narraciones de los sirio libaneses que dieron lugar a su arraigo en el noroeste argentino, llegando a ser la tercera colectividad más importante después de la italiana y española. Otros investigadores apuntan al carácter "exótico" que se le había atribuido en la ciudad de Buenos Aires, las que llevaron a su desplazamiento.

Su llegada se relaciona y facilita con el ferrocarril y el comercio trashumante de objetos para luego establecerse en el de ramos generales. Su migración obedece a cadenas migratorias familiares, pero no hay datos confiables porque eran considerados "turcos" "otomanos" o árabes de manera general en los registros de ingreso.

La presencia italiana y española es importante, aunque no tan numerosa como en Córdoba y Rosario, pero crearon instituciones que dejaron panteones en el cementerio municipal. Se dedicaron a la actividad agropecuaria, a pequeños comercios de productos y una parte a la minería. 
El cementerio judío, se encuentra también en la ciudad y fue construido en 1930, por la "Asociación Israelita Sefaradí Catamarqueña de Socorros Mutuos", judíos llegados de Alepo (Siria). En la década del 40 arriban judíos ashkenazis que conforman una sede de la AMIA, que administra el cementerio en la actualidad (Dulout, 2018)

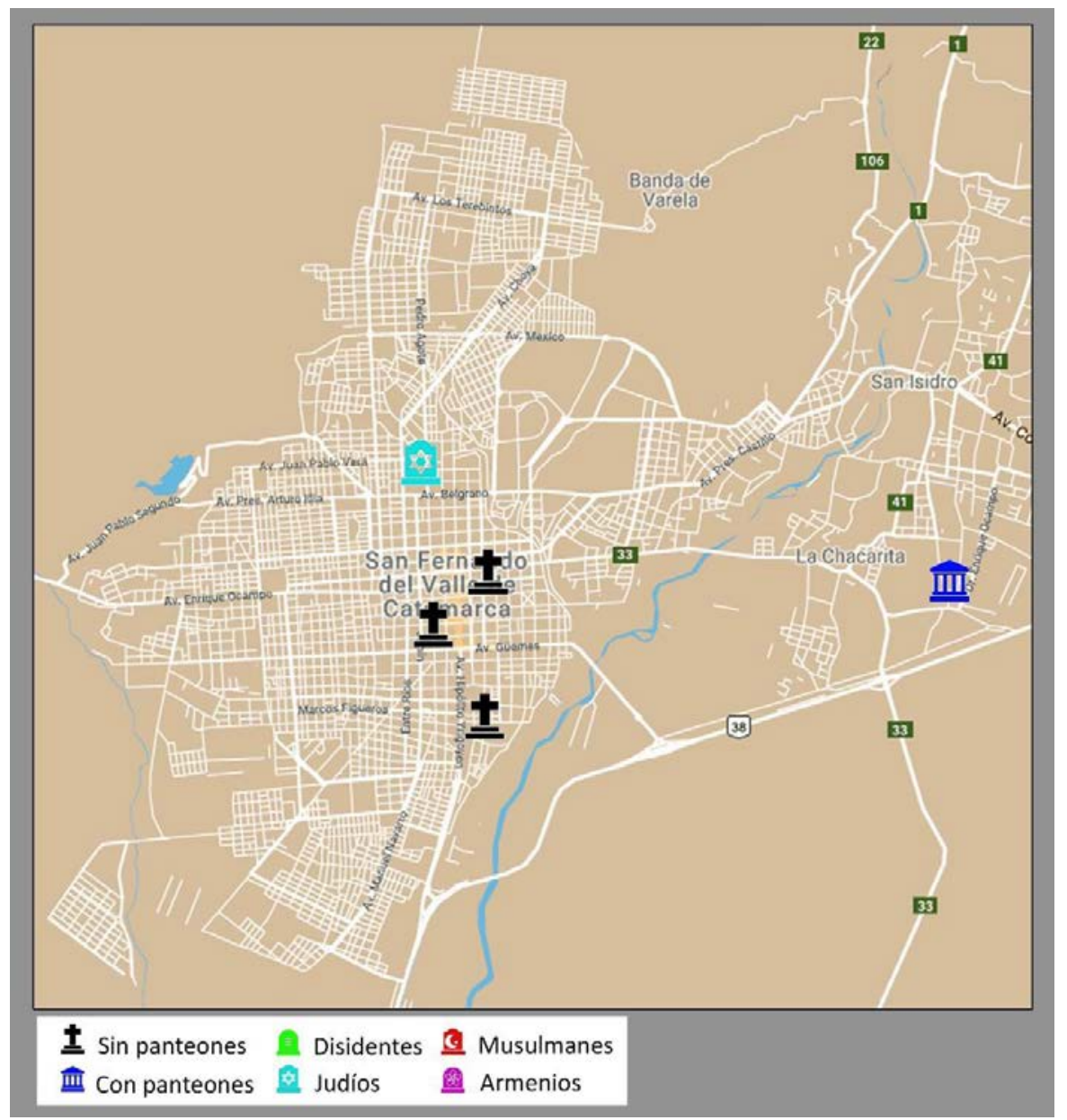

Figura 10. Cementerios de San Fernando del Valle de Catamarca y alrededores. Fuente: Elaboración propia, sobre base de Gmaps, 2019.

\section{Reflexiones provisorias}

Los cementerios son espacios complejos con un valor simbólico multivalente, que cobran rigurosidad y estructura normativa a fines del siglo XIX.

Son espacios ambiguos, heterotópicos (Foucault, 1966), que suman capas y permiten superponer aspectos de modernidad y otros que se anclan en la historia más remota. De manera que coincidimos con Foucault cuando los denomina como "contraespacios", la otra cara de la ciudad de los vivos, permitiendo construir sentidos diversos sobre lo construido, alterado por la imaginación y la memoria, poniendo en crisis el espacio en que vivimos; uniendo lo cotidiano con la historia.

Los cementerios se construyen en base al contexto, pero también con características que emanan de su propia cultura, yuxtaponiendo, por un lado, capas de fuerte carga simbólica y al mismo tiempo constituyéndose como espacios específicos de prácticas emocionales (Vidor, 2014). El rito se constituye como un momento reparador, que 
ubica las emociones en un determinado momento y lugar, que transforma al difunto en "pionero", "miembro fundador", "ancestro" incorporándolo a la historia comunitaria, pasando a formar parte de una cadena de sentido y de un proceso más amplio en el que se inscribe. Estos lugares "le hablan" y le comunican a los deudos, a los descendientes, a los miembros de su asociación así como también a las otras comunidades, evidenciando un poder y un capital social que les permite construir un espacio con una profunda carga identitaria. Así, los viajes a la sociedad de origen tenían la misión de traer encajes, rosarios, cruces, réplicas, tierra de la aldea o pueblo, piedras e incluso semillas que crearan el ambiente performativo de los cementerios recordados y recreados con fragmentos y detalles.

De todas maneras, la libertad de esa ritualidad en la modernidad se encuentra anclada y delimitada en los espacios definidos por los Estados. El cementerio es un espacio político y al mismo tiempo es producto de una necesidad social y moldeado por aspectos de la modernidad vinculados a la gestión del territorio, el discurso médico, la concepción de Estado Nación y sus leyes, así como el discurso religioso que habitualmente patrocina ese espacio.

De manera que coincidimos con la definición de Magariños de Moretín y Shimko (2006:96) de que el cementerio es un tipo particular de "puesta en escena" que compone una semiótica indicial

constituida por objetos y comportamientos con eficacia de signos (incluyendo en ellos las manifestaciones escritas $u$ orales de los textos verbales intervinientes), proporcionando los instrumentos analíticos y metodológicos específicos para explicar el proceso por el cual una determinada comunidad atribuye un determinado significado a un determinado cementerio.

Es decir, hay aspectos técnicos (desembarazarse del fallecido) y otros actos propiamente simbólicos que se expresan y que poseen la fuerza que la comunidad le atribuye. De manera que tanto los objetos como los comportamientos son partes que funcionan de manera dialéctica componiendo un espacio performativo. Modificando el ambiente "irrumpiendo" con sectores en otro idioma, con otras cruces, con otros materiales estableciendo nuevas territorialidades.

No es una novedad que el lugar que se le da a la muerte es, en el presente, menos significativo que hace unos años, sin embargo, casi en su totalidad, estos lugares permanecen activos.

Los cementerios de disidentes, como espacios comprados, cedidos o donados por miembros de la comunidad pudieron armar su propio escenario heterotópico, en donde la sobriedad del rito y la vuelta a la tierra tuvieran un lugar de destino, en virtud de la prohibición de inhumación en los cementerios municipales, reforzando su identidad religiosa y étnica. Esta libertad dentro del espacio permitió, además, lápidas en su idioma o dialecto nativo, así como cruces celtas y ornamentos en piedra y madera.

Los cementerios judíos, por otro lado, tenían un tipo de entierro ideal en su propia patria, que ya no podían cumplir, de manera que otorgarles el mejor reposo posible fue una de las principales preocupaciones comunitarias que lograron en todos los lugares de asentamiento.

A fines del XIX, los cementerios municipales son reservorios de una de las principales funciones de la iglesia ya que a medida que la cultura laicista de la Generación del 80 restaba responsabilidades al clero, éstos continuaban siendo lugares específicos para llevar a cabo rituales funerarios. Es decir, antes de los cambios, gran parte de los 
rituales se desplegaban en los espacios domésticos, y a partir de 1870, estas funciones se desplazan a un lugar específico, preparado para el tratamiento profesional del procedimiento. A ello se suma, que en las últimas décadas del XIX ya comienzan a funcionar las casas funerarias que ofrecían servicios que permiten, además, evidenciar el capital simbólico del fallecido (carruajes, caballos, bandas), que median entre los espacios de muerte institucional (asilos, hospitales). Las comunidades, italianas, francesas y sirio libanesas, que profesaban la fe católica, encuentran un espacio afín dentro de los cementerios municipales, desarrollando sus propias actualizaciones identitarias que no desentonan con las locales, siendo presencias numerosas dentro del espacio. Asimismo, una forma de demostrar su capital social se realizaba a través de los panteones, algunos monumentales.

Las asociaciones italianas y españolas poseen un elemento distintivo con respecto a otros grupos porque en función de las dos guerras mundiales y la civil española, retroalimentan hasta mediados del siglo XX las asociaciones que ya habían alcanzado un alto grado de dispersión en el territorio y una red densa de solidaridades y funciones.

Si observamos los resultados cuantitativos, podemos decir que el 37\% son cementerios municipales católicos sin panteones (aunque un número importante de ellos posee placas de ASM); el 9\% de los recorridos son de disidentes, el 9\% judíos, el 2\% no fueron analizados, pero corresponden a dos cementerios musulmanes y un armenio; y por último el $43 \%$ son cementerios con panteones asociativos. Si sumamos los que poseen una marca de nacionalidad y evidencien su identidad étnico religiosa, los últimos cuatro, el porcentaje es mayor (63\%) (Ver Anexo). De manera que son varias y diversas las líneas a seguir a futuro, a fin de completar el relevamiento, así en sus aspectos simbólicos y materiales, y profundizar en la importancia de estos espacios para las comunidades y las formas en las que se han modificado los rituales y representaciones por el contexto migratorio.

De acuerdo a lo relevado, si bien parcial, se puede observar una representación importante en los pueblos y ciudades recorridas, evidenciando que la muerte, dentro del contexto migratorio es plural, y las formas de celebrarla poseen un impacto social que no pasa desapercibida para el grupo: transforma los lugares recreando escenarios lejanos y cada acto que se haga en función del fallecido, es un mensaje para propios y ajenos, que comunica y reviste de sentido la ausencia, al otro lado del océano. 


\section{Q Bibliografía}

" Adam, S., Eilers, G. y Carrasquero, S. (2013). Cementerio de disidentes: un espacio social y urbanístico diferente en Azul, provincia de Buenos Aires. En Flores O. (Comp.) Cementerios, patrimonio y memoria. La Plata: Red Argentina.

» AMIA (2018). Recuperado de http://www.amia.org.ar/Amia/index.php/news/ default/show/news/3879 Última vista: (10/02/19)

» Ariès, P. (2000). Historia de la muerte en occidente. Barcelona: El Acantilado

»Barile, C. y Castiglione, M. C. (2018). Morir no es poco. Estudios sobre la muerte y los cementerios. CABA: Ed. Continente.

»Bjerg, M. (2001). Entre Sofie y Tovelille. Una historia de los inmigrantes daneses en la Argentina (1848-1939). Buenos Aires: Biblos.

"Bjerg, M. (2010). Historias de la inmigración en la Argentina. Buenos Aires: EDHASA.

» Bourdieu, P. (1987). Los Tres Estados del Capital Cultural. En Sociológica, UAMAzcapotzalco, México, 5, pp. 11-17.

»Carbonetti, A. (2015). Políticas estatales, medicina e iglesia frente a la epidemia de cólera de 1867-1868 en Córdoba y Rosario. Recuperado de (http:// historiapolitica.com/datos/biblioteca/medicosXIX_carbonetti.pdf). (12/01/18).

" Castiglione, M. C. (2016). Morir en comunidad. La historia del panteón de la Asociación Española de Socorros Mutuos de Belgrano. Revista de Estudios Migratorios Latinoamericanos, 30, 80, Enero-Junio.

"Castiglione, M. C. (2017). Representaciones de la ausencia: la historia del Panteón de la Asociación Española de Socorros Mutuos de Rosario, 1857-1885. Revista Estudios de Historia de España del Instituto de Historia de España, XIX, 291-320.

" Castiglione, M. C. (2018). La ruta de los pioneros irlandeses (1820-1880) y sus representaciones funerarias en los cementerios municipales. En Morir no es poco. Estudios sobre la muerte y los cementerios. CABA: ED. Continente.

" Castiglione, M.C. (2019). Verde y gris. Un recorrido por los Cementerios de Disidentes (1833-1914). Revista Textos y contextos desde el sur. Universidad Nacional de San Juan Bosco, 4 (7), pp.35-55.

»Cravino, A. (2014). La noción de heterotopía y su aplicación al análisis de la enseñanza del proyecto en la escuela de arquitectura de Buenos Aires, 19011948). Anales del IAA, 44, 33-48.

»Dal Castello, D. (2014). Dejar la casa. Espacios de los velorios en Buenos Aires 1868-1903. En Anales del IAA, 44, 161-175.

»Devoto, F. (2003). Historia de la Inmigración en la Argentina. Buenos Aires: Sudamericana.

»Djenderedjian, J. (2016). Los pobladores de la Colonia y la inmigración en los primeros años de vida independiente. En Los inmigrantes en la construcción de la Argentina. Buenos Aires: OIM.

"Dulout, L. (2011). El cementerio israelita de La Plata. En El cementerio de La plata y su contexto histórico. Comp. Sempé, C. y Flores, O. La Plata-Ringuelet: el autor. 
"Dulout, L. (2018). El Cementerio judío de Catamarca. En Actas del XIX Encuentro Iberoamericano de valoración y gestión de Cementerios Patrimoniales. Cochabamba, EP de Bolivia, 6 al 11 de noviembre. (En prensa)

»Durkheim, E. (1989 [1897]). El Suicidio. Buenos Aires: AKAL.

»Elías, N. (1989) La soledad de los moribundos. México: FCE.

» Fiquepron, M. (2015). Cadáveres, epidemias y funerales en Buenos Aires, 18561886. En G. Kessler, G. y Gayol, S., Muerte, política y sociedad en la Argentina, Buenos Aires, Edhasa.

» Frid de Silberstein, C. (1985). Mutualismo y educación en Rosario: las escuelas de la Unione e Benevolenza y de la Sociedad Garibaldi (1874-1911). Estudios Migratorios Latinoamericanos, 1 (1985), p. 77 - 97

" Frid de Silberstein, C. (1988). Educación e identidad. Un análisis del caso italiano en la provincia de Santa Fe (1880-1920). En Devoto, F y Rosoli, G. (eds.), L'Italia nella società Argentina, Roma: Centro Studi Emigrazione.

"Flores, O. y Dulout, L. (2006). Costumbres tradicionales funerarias judías y su visualización dentro del Cementerio israelita de La Plata. En Patrimonio cultural en cementerios y rituales de la muerte. $1^{\underline{a}}$. Ed. Bs. As: GCBA

»Foucault, M. (2010 [1966]). El cuerpo utópico. Las heterotopías. Buenos Aires: Nueva Visión.

»Grimson, A. (2000). Interculturalidad y comunicación. Buenos Aires: Norma.

» Iwaniszewski, S. y Vigliani, S. (2011) Identidad, paisaje y patrimonio. México DF: INAH.

»López Mato, O. y Couto, C. (2015). Fiebre amarilla. CABA: Olmo Ediciones.

»Lull, V. y Picazo, M. (1989). Arqueología de la muerte y estructura social. AEspA, 62, 5-20.

» Magariños De Moretin, J. y Shimko, S. (2006). Acerca de la calidad semiótica de los cementerios; con especial atención al Cementerio de la Ciudad de La Plata. En Patrimonio cultural en cementerios y rituales de la muerte. Bs. As.: GCBA

»Maronese, L. (2006). Flores 200 años. Barrio y Cementerio - 1a ed. - Buenos Aires: Ministerio de Cultura - Gobierno de la Ciudad Autónoma de Buenos Aires.

» Melella, C. (2016). Migrantes de países andinos en la Argentina. Buenos Aires: Biblos.

» Mera, C. (2016). Migración coreana y china en Argentina, 1960-200o. En Los inmigrantes en la construcción de la Argentina. Buenos Aires: OIM.

» Montañez, G. (1997). Geografía y ambiente: enfoques y perspectivas. Santa Fe de Bogotá: Universidad de la Sabana.

» Reimers, E. (1999). Death an identity: graves and funerals as cultural communication. Mortality, 4 (2), 147-166.

"Terán, O. (1987). Positivismo y nación en la Argentina. Ed. Puntosur, Buenos Aires

»Terán, O. (2000). Vida intelectual en el Buenos Aires de fin de siglo (1880-1910). Buenos Aires: FCE.

» Thomas, L. V. (1983). Antropología de la muerte. Ciudad de México: FCE.

» Trumpet, P. y Griffiths, R. (2011). La economía moral de la muerte en el siglo XIX. Cruce de perspectivas sobre Francia e Inglaterra. El movimiento social 4 (237), 33-54. 
»Solá, N. y Giménez, C. (2018). El cementerio El Salvador de Rosario (1860-189o). Discursos y prácticas en torno a la muerte. En Morir no es poco. Estudios sobre la muerte y los cementerios. CABA: ED. Continente.

»Vidor, G. M. (2014) Satisfying the mind and inflaming the heart: emotions and funerary epigraphy in nineteenth century Italy. Mortality, 19 (4), 342-360.

\section{Celeste Castiglione / castiglioneceleste@yahoo.com.ar}

Lic. en Ciencia Política (FSOC-UBA) y en Sociología (FSOC-UBA), Posgrado en Ciencia Política y Sociología (FLACSO) y doctora en Ciencias Sociales (UBA). Es investigadora adjunta de CONICET con sede en el IESCODE-UNPAZ, vicepresidenta de la Asociación Argentina de Estudios Coreanos (AAEC). Profesora de grado y posgrado, ha publicado artículos y libros vinculados a la temática migratoria y las representaciones sociales de la muerte. 


\section{Q Anexo}

\begin{tabular}{|c|c|c|c|c|c|c|c|c|c|c|c|c|}
\hline & Sin Panteones & Disidentes & Judíos & $M$ & A & $\begin{array}{c}\text { Cementerios } \\
\text { con Panteones }\end{array}$ & $E$ & I & $\mathrm{F}$ & SL & 0 & Total \\
\hline \multirow{3}{*}{ 㐫 } & & Chacarita Inglés & & $*_{1}$ & $*_{2}$ & Chacarita & 10 & 4 & 2 & & 3 & 5 \\
\hline & & Alemán & & & & Flores & 1 & 1 & & & & \\
\hline & & & & & & Recoleta & 1 & & & & 1 & \\
\hline \multirow{17}{*}{ 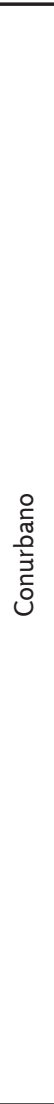 } & Berazategui & $\begin{array}{c}\text { Lomas de } \\
\text { Zamora }\end{array}$ & Avellaneda & & & Avellaneda & & 1 & & & & 39 \\
\hline & E. Echeverria & $\begin{array}{l}\text { Malvinas Arg- } \\
\text { Pablo Nogués }\end{array}$ & $\begin{array}{l}\text { La Matanza- } \\
\text { Ciudadela }\end{array}$ & & & Alte. Brown & 1 & 3 & & & 1 & \\
\hline & Ezeiza & Quilmes & Berazategui & & & $\begin{array}{l}\text { Lomas de } \\
\text { Zamora }\end{array}$ & 1 & 2 & & & & \\
\hline & F. Varela & & $\begin{array}{l}\text { La Matanza- La } \\
\text { Tablada }\end{array}$ & & & $\begin{array}{l}\text { Merlo-Santa } \\
\text { Isabel }\end{array}$ & 1 & 1 & 1 & & & \\
\hline & Hurlingham & & $\begin{array}{l}\text { La Matanza- } \\
\text { Sefaradí }\end{array}$ & & & Moreno & 1 & 1 & 1 & & & \\
\hline & Ituizango & & $\begin{array}{l}\text { Lomas de } \\
\text { Zamora- } \\
\text { israelita }\end{array}$ & & & Morón & 1 & 1 & & 1 & & \\
\hline & José C. Paz & & $\begin{array}{l}\text { Lomas de } \\
\text { Zamora- } \\
\text { sefaradí }\end{array}$ & & & San Isidro & & 1 & & & & \\
\hline & $\begin{array}{c}\text { La Matanza San } \\
\text { Justo }\end{array}$ & & & & & San Martín & 1 & & & & & \\
\hline & $\begin{array}{l}\text { La Matanza- } \\
\text { Villegas }\end{array}$ & & & & & San Miguel & & 1 & & & & \\
\hline & Lanús & & & & & Tigre & & & & & & \\
\hline & Malvinas Arg. & & & & & & 2 & 1 & & & & \\
\hline & Merlo- Libertad & & & & & & & & & & & \\
\hline & Quilmes & & & & & & & & & & & \\
\hline & San Fernando & & & & & & & & & & & \\
\hline & $\begin{array}{l}\text { San Isidro- } \\
\text { Boulogne }\end{array}$ & & & & & & & & & & & \\
\hline & Tigre & & & & & & & & & & & \\
\hline & Tres de Febrero & & & & & & & & & & & \\
\hline \multirow{15}{*}{$\begin{array}{l}\dot{x} \\
\dot{\varphi}\end{array}$} & Alem & Azul & Carlos Casares & & & 25 de Mayo & & 1 & & & & 99 \\
\hline & Ameghino & Baradero & $\begin{array}{c}\text { Gral. } \\
\text { Pueyrredón }\end{array}$ & & & 9 de Julio & & 1 & & & & \\
\hline & Baradero & Castelli & $\begin{array}{l}\text { Mercedes } \\
\text { (Espacio) }\end{array}$ & & & Alberti & & 1 & & & & \\
\hline & Berisso & Chascomús & La Plata & & & Arrecifes & 1 & 1 & & & 1 & \\
\hline & Cañuelas & Olavarría & & & & Ayacucho & 1 & & & & & \\
\hline & Carlos Casares & Tandil (Espacio) & & & & Azul & & 2 & & & & \\
\hline & Carlos Tejedor & & & & & Balcarce & 1 & 1 & 1 & & & \\
\hline & Chacabuco & & & & & Baradero & 1 & 1 & 1 & & & \\
\hline & Ensenada & & & & & $\begin{array}{l}\text { Bolívar } \\
\text { (Espacio) }\end{array}$ & 1 & & & & & \\
\hline & Escobar & & & & & Bragado & 2 & 2 & & & & \\
\hline & Gra. Guido & & & & & Campana & 1 & & & & & \\
\hline & Gral. Alvear & & & & & $\begin{array}{c}\text { Cap. } \\
\text { Sarmiento }\end{array}$ & 1 & 1 & & & & \\
\hline & Gral. Guido & & & & & $\begin{array}{l}\text { Carmen de } \\
\text { Areco }\end{array}$ & 1 & & & & & \\
\hline & Gral. Las Heras & & & & & Castelli & 1 & 1 & & & & \\
\hline & Gral. Lavalle & & & & & Chascomús & 1 & & & & & \\
\hline
\end{tabular}




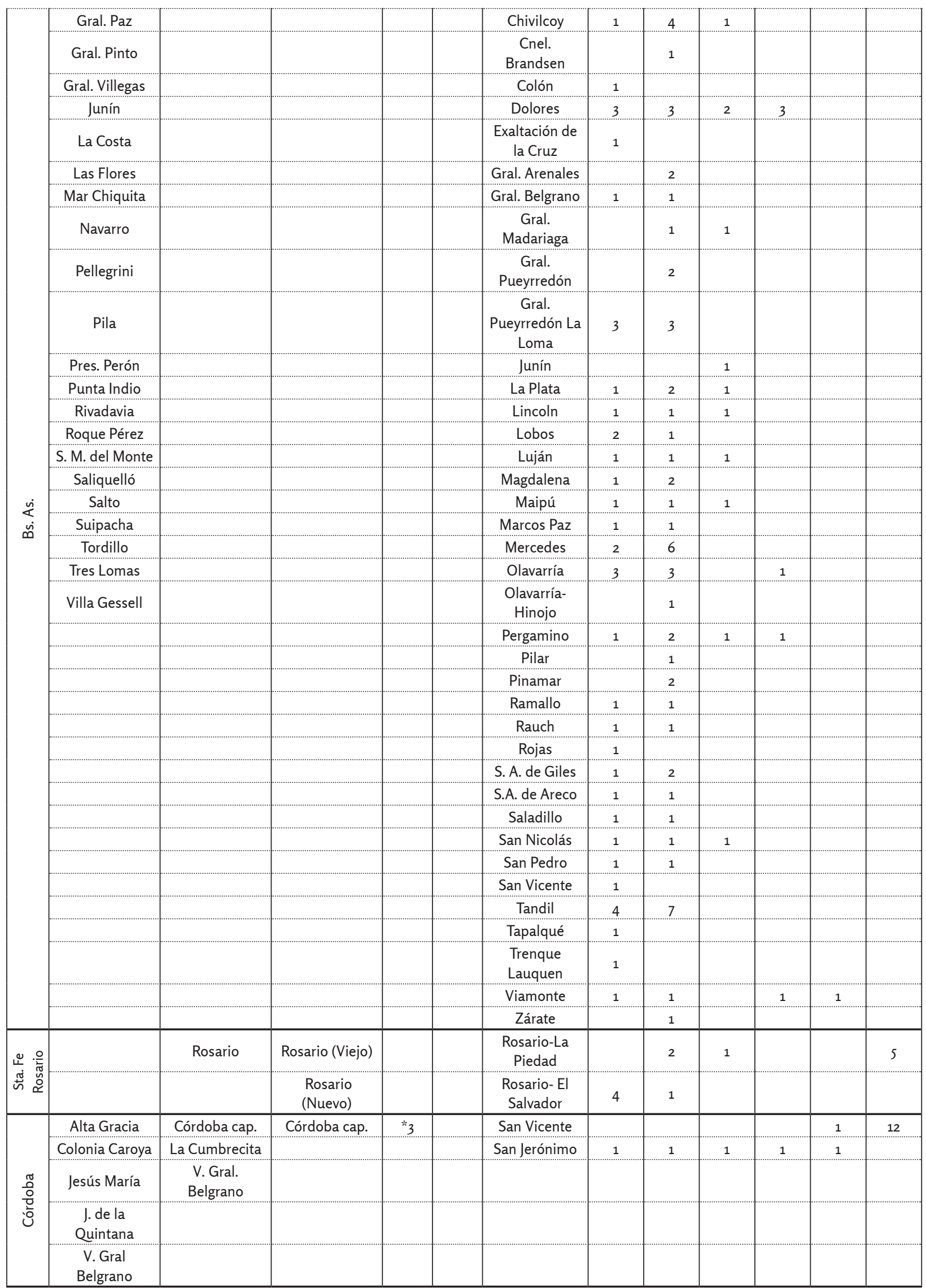




\begin{tabular}{|c|c|c|c|c|c|c|c|c|c|c|c|c|}
\hline \multirow{3}{*}{ 心 } & $\begin{array}{l}\text { S.F. Catamarca } \\
\text { San José }\end{array}$ & & SF Catamarca & & & S.F. Catamarca & 1 & 1 & & 1 & & 5 \\
\hline & La Tercena & & & & & & & & & & & \\
\hline & Valle Viejo & & & & & & & & & & & \\
\hline \multicolumn{2}{|c|}{ Sub total panteones } & & & & & & 78 & 92 & 19 & 9 & 9 & \\
\hline 丞 & 61 & 15 & 15 & 2 & 1 & 71 & & & & & & 165 \\
\hline $5^{\circ}$ & $37 \%$ & $9 \%$ & $9 \%$ & $2 \%$ & $43 \%$ & & & & & & & $100 \%$ \\
\hline & $37 \%$ & $63 \%$ & & & & & & & & & & $100 \%$ \\
\hline
\end{tabular}

Referencias:

*1 y 3 : Musulmanes

*2 Armenio

E: Españoles

I: Italianos

F: Franceses

SL: Sirio libaneses

O: Otros 